\title{
Health-related quality of life and social constraints among Chinese breast cancer patients: a cross-sectional study
}

\author{
Chunying Cui ${ }^{1}$, Lie Wang ${ }^{1}$ and Xiaoxi Wang ${ }^{2^{*}}$ (D)
}

\begin{abstract}
Background: Most research studying social constraints has been performed among Caucasian or Asian American breast cancer (BC) patients, but few studies have evaluated social constraint levels and explored the effect of social constraints on the integrative health-related quality of life (HRQOL) of Chinese BC patients. Therefore, our study aimed to examine the association of social constraints with $\mathrm{HRQOL}$ among Chinese women with BC.
\end{abstract}

Methods: This was a cross-sectional study of 136 Chinese women diagnosed with BC in Liaoning Province, China, from December 2020 to May 2021. Questionnaire information contained HRQOL, social constraints, social support, social stigma, and sociodemographic and clinical characteristics. Multiple linear regression was used to analyse the association of psychological factors with HRQOL.

Results: The mean score of FACT-B was 96.05 (SD = 18.70). After controlling for potential confounders, social constraints (Beta $=-0.301, P<0.001$ ) and social stigma (Bet $a=-0.241, P=0.001$ ) were negatively associated with $\mathrm{HRQOL}$ and social support (Beta $=0.330, P<0.001$ ) was positively associated with $\mathrm{HRQOL}$, which explained $44.3 \%$ of the variance in HRQOL.

Conclusions: The findings of the current study suggest that Chinese BC patients' HRQOL needs to be enhanced after treatment. Social constraints have a strong association with HRQOL. Intervention strategies focusing on less personal disclosure should be considered to avoid social constraints and improve HRQOL among Chinese patients with BC.

Keywords: Health-related quality of life, Social constraints, Social support, Social stigma, Chinese, Breast cancer

\section{Introduction}

Breast cancer $(\mathrm{BC})$ is the most frequently diagnosed cancer and the leading cause of cancer death in the vast majority of countries. According to the most recent GLOBOCAN publication, the five most frequent cancers in Chinese women are breast, lung, colorectum, thyroid and stomach [1]. It was estimated in 2020 that the agestandardized (world) incidence of BC was 39.10/100,000

\footnotetext{
*Correspondence: xiaoxiwang@cmu.edu.cn

${ }^{2}$ Medical Basic Experimental Teaching Center, China Medical University,

No. 77 Puhe Road, Shenyang North New Area, Shenyang 110122, Liaoning, People's Republic of China

Full list of author information is available at the end of the article
}

in China [2]. Furthermore, there are approximately 416,371 new BC cases and 117,174 deaths per year among Chinese women [2]. Due to early screening, early diagnosis and better treatment, patients with $\mathrm{BC}$ have a long survival time after diagnosis. Studies have reported that breast-conserving surgery and adjuvant radiotherapy in early $\mathrm{BC}$ patients result in 5-year overall survival rates of $>80 \%$ in China [3, 4]. As BC patients live longer, concerns about quality of life have increased. Hence, it is urgent and significant to evaluate and improve the health-related quality of life (HRQOL) of $\mathrm{BC}$ patients after treatment.

At present, BC treatment involves state-of-art biomedical therapy but can fail to address HRQOL issues, original author(s) and the source, provide a link to the Creative Commons licence, and indicate if changes were made. The images or other third party material in this article are included in the article's Creative Commons licence, unless indicated otherwise in a credit line to the material. If material is not included in the article's Creative Commons licence and your intended use is not permitted by statutory regulation or exceeds the permitted use, you will need to obtain permission directly from the copyright holder. To view a copy of this licence, visit http://creativecommons.org/licenses/by/4.0/. The Creative Commons Public Domain Dedication waiver (http://creativecommons.org/publicdomain/zero/1.0/) applies to the data made available in this article, unless otherwise stated in a credit line to the data. 
particularly emotional well-being and social/family well-being after diagnosis and treatment. Doege et al. conducted a study to compare disease-free BC patients' HRQOL to that of non-cancer female controls and found that long-term $\mathrm{BC}$ survivors suffer significantly lower social, emotional, functional, physical well-being, fatigue, insomnia, and dyspnoea than female population controls [5]. However, a study conducted by Bower et al. indicated that many $\mathrm{BC}$ patients have relatively healthier lifestyles and found a new meaning to their lives in the long term [6]. In addition, long-term survivors reported similar or improved HRQOL levels based on exercise interventions compared to controls without BC [7]. Some sociodemographic and clinical characteristics among $\mathrm{BC}$ patients affect their HRQOL, including age [8], socioeconomic status (SES) [9], cancer stage [10] and treatment methods [11]. Moreover, an increasing number of investigators have focused on studying sociopsychological factors related to HRQOL among BC patients [5-8, 12, 13].

Most evidence has shown that low social support and high social stigma are importantly and significantly associated with impairments in HRQOL among BC patients $[9,13-15]$. Social support refers to a combination of perceiving assistance available from family, friends and other significant relationships in times of need [16]. Based on the theory of the "stress buffering hypothesis" [17], social support can enhance individuals' well-being and health by acting as a "direct agent". In addition, it can act as an "antecedent factor" to increase individuals' positive coping styles and psychological empowerment, which thus has a positive effect on mental health and HRQOL. For example, Strayhorn SM thought that positive social support has a positive association with HRQOL in BC patients [15]. In other words, social support is a positive psychological resource to evaluate BC patients' HRQOL. Stigma is defined as feelings of isolation, degradation, criticism and rejection during personal experience and a social process that affects psychological, physical and social adjustment [18]. Indeed, previous studies have found that people with stigma have worse health outcomes than their non-stigmatized counterparts [19, 20]. A growing number of studies have examined stigma associated with cancer as cancer is perceived more negatively in society than some other diseases [21]. Cancer treatment leaves psychological and physical scars, such as stigma, surgical scars and hair loss [22]. BC patients with perceived stigma may avoid social relationships, which may result in an interpersonal stressor [23]. More importantly, perceived stressors may influence HRQOL among $\mathrm{BC}$ patients.

There is some evidence that social constraints have a strong association with decreased HRQOL and increased emotional distress among women with $\mathrm{BC}[9,24,25]$.
Social constraints are defined as the objective existence and subjective perceptions of social conditions, which hinder individuals from disclosing or modifying the ways of their disclosure of illness-related feelings or concerns [26]. Based on social cognitive processing theory [26, 27], individuals' cognitive assimilation or accommodation of cancer experience can be facilitated by emotional disclosure (talking with empathic and supportive others, providing reappraisal, validation and meaning-making); cognitive processing thereby contributes to improving mental adjustment to cancer within a receptive social environment. When cancer patients experience unsatisfying interpersonal factors (others' withdrawal, criticism and denial), an opposing effect occurs. Additionally, social constraints negatively affect healthy behaviours, including self-examination among BC patients [27], adherence to self-care activities among diabetes patients [28], and exercise [29]. However, most research studying social constraints has been performed among Caucasian or Asian American BC cancer patients, and few studies have evaluated social constraint levels and explored the effect of social constraints on integrative HRQOL among Chinese BC patients living in mainland China. There is only a study conducted by Yeung et al. [30] to explore the adverse effect of social constraints on functional wellbeing among BC patients living in Shandong Province, China. Owing to cultural differences, Chinese emotional disclosure is difficult to practice. Namely, Chinese people are more likely to value emotional suppression to avoid disturbing the interpersonal harmony that Chinese society emphasizes, whereas people from Western cultures tend to express their emotions due to the independent culture $[31,32]$. Therefore, our study aimed to examine the association of social constraints with HRQOL among Chinese women with BC.

\section{Methods \\ Participants}

The present study included 136 Chinese women diagnosed with $\mathrm{BC}$ in Liaoning Province, China, from December 2020 to May 2021. Their average age was 48.05 $(\mathrm{SD}=10.24)$. Among the recruited participants, $77.2 \%$ lived in cities, and $66.2 \%$ had an educational background of senior middle school or above. The majority of participants $(85.3 \%)$ were married/cohabiting, and more than $50 \%$ of participants had a family per capita monthly income above 3000 (CNY). Of them, 23.5\% had a time since diagnosis above two years. All patients had initial stage I (36\%) or stage II $(64 \%)$; about $50 \%$ of patients subsequently developed distant metastases after stopping treatment. Details of sociodemographic and clinical information are presented in Table 1. 
Table 1 Sociodemographic and clinical information among Chinese BC patients

\begin{tabular}{|c|c|c|}
\hline Variables & $\mathbf{N}$ & Percent (\%) \\
\hline Age & 136 & $48.05(10.24)(30-78)^{*}$ \\
\hline \multicolumn{3}{|l|}{ Residence } \\
\hline Rural area & 31 & 22.8 \\
\hline City & 105 & 77.2 \\
\hline \multicolumn{3}{|l|}{ Education background } \\
\hline Junior middle and below & 46 & 33.8 \\
\hline Senior middle school & 63 & 46.3 \\
\hline College and above & 27 & 19.9 \\
\hline \multicolumn{3}{|l|}{ Marriage status } \\
\hline Single/divorced/widowed/separated & 20 & 14.7 \\
\hline Married/cohabited & 116 & 85.3 \\
\hline \multicolumn{3}{|l|}{ Employment } \\
\hline Yes & 60 & 44.1 \\
\hline No & 37 & 27.2 \\
\hline Retirement & 39 & 28.7 \\
\hline \multicolumn{3}{|l|}{ Family per capita monthly income (CNY) } \\
\hline Less than 3000 & 58 & 42.6 \\
\hline $3000-5000$ & 43 & 31.6 \\
\hline More than 5000 & 35 & 25.7 \\
\hline \multicolumn{3}{|l|}{ Children } \\
\hline No & 10 & 7.4 \\
\hline Yes & 126 & 92.6 \\
\hline \multicolumn{3}{|l|}{ Religious faith } \\
\hline No & 126 & 92.6 \\
\hline Yes & 10 & 7.4 \\
\hline \multicolumn{3}{|l|}{ Period } \\
\hline Normal & 36 & 26.5 \\
\hline Disorder & 16 & 11.8 \\
\hline Amenorrhea & 84 & 61.8 \\
\hline \multicolumn{3}{|l|}{ Smoking } \\
\hline No & 129 & 94.9 \\
\hline Yes & 7 & 5.1 \\
\hline \multicolumn{3}{|l|}{ Drinking } \\
\hline No & 106 & 77.9 \\
\hline Yes & 6 & 4.4 \\
\hline Quitting & 24 & 17.6 \\
\hline \multicolumn{3}{|l|}{ Time since diagnosis } \\
\hline Half year or below & 47 & 34.6 \\
\hline Half to 2 years & 57 & 41.9 \\
\hline More than 2 years & 32 & 23.5 \\
\hline \multicolumn{3}{|l|}{ Distant metastasis ${ }^{\mathrm{a}}$} \\
\hline No & 65 & 47.8 \\
\hline Yes & 71 & 52.2 \\
\hline \multicolumn{3}{|l|}{ Cancer stage ${ }^{b}$} \\
\hline | & 49 & 36.0 \\
\hline$\|$ & 87 & 64.0 \\
\hline
\end{tabular}

a Subsequent development of distant metastases

${ }^{\mathrm{b}}$ Disease stage at diagnosis

${ }^{*}$ Mean (SD) (range)

\section{Procedures}

This study had a cross-sectional design. All participants were recruited at Shengjing Hospital of China Medical University. The inclusion criteria for the present study were as follows: (1) participants were diagnosed with BC; (2) they received treatments, such as breast-conserving surgery and/or adjuvant radiotherapy; and (3) they could communicate fluently in Chinese and voluntarily participate in the survey. The exclusion criteria were as follows: (1) other severe diseases (other cancers) and (2) a history of psychiatric or cognitive disorders. In total, 212 patients met our inclusion criteria, and 150 participants provided written informed consent to participate in our study. After obtaining informed consent for the present study, investigators distributed the questionnaires to the participants. In addition, medical information was collected from their clinical records. Finally, 136 valid questionnaires were recovered after excluding 14 questionnaires with poorly answered responses. The effective response rate of the questionnaires was $90.7 \%$.

\section{Measures \\ Health-related quality of life (HRQOL)}

The Chinese simplified version of the Functional Assessment of Cancer Therapy-Breast (FACT-B) Version 4.0 was used to assess BC patients' HRQOL [33]. The scale contains 36 items to measure BC patients' physical (PWB, seven items), emotional (EWB, six items), social/ family (SFWB, seven items), functional well-being (FWB, seven items), and concerns about BC (BCS, nine items) [33, 34]. Each item was scored on a five-point scale from 0 (not at all) to 4 (extremely). According to a previous study $[14,35]$, the FACT-B total score $=P W B+S$ $\mathrm{WB}+\mathrm{EWB}+\mathrm{FWB}+\mathrm{BCS}$. A higher score reflects better HRQOL. In our study, the aim was to examine the effect of social factors (social constraints, social support and social stigma) on the integrative health-related quality of life (HRQOL) among Chinese BC patients. Therefore, we mainly discuss the associations of social factors with HRQOL based on the total score of FACT-B.

\section{Social constraints}

The current study used the 15-item Social Constraints Scale (SCS-15) to test BC patients' social constraints in the past month [36]. You and Lu translated the SCS15 from English to Chinese [24], and the scale has been confirmed to have good reliability and validity among Chinese American BC patients $[9,25]$. The scale aims to measure the frequency with which individuals diagnosed with cancer feel socially constrained when discussing their cancer-related thoughts from their spouse (family or friends for patients without a spouse). Two items (tell 
you not to worry so much about your health; tell you to try not to think about the cancer) were deleted due to low item-total correlations $(r=0.188-0.235)$ compared to other items $(r=0.474-0.757)$, which is consistent with a previous study [37]. Therefore, there are 13 items in the present study, and each item is rated on a four-point scale from 1 (never) to 4 (often). A higher score indicates a higher frequency of experiencing social constraints.

\section{Social support}

The Chinese version of the Multidimensional Scale of Perceived Social Support (MSPSS) was used to measure the level of social support in BC patients [38] and has been widely used in other diseases [39]. The scale comprises 12 items, and the rating was made on a seven-point scale from 1 (very strongly disagree) to 7 (very strongly agree), with a higher score indicating sufficient support from family, friends or significant others.

\section{Social stigma}

The Chinese version of the Social Impact Scale (SIS) [40] was used to evaluate the level of stigmatization among patients with $\mathrm{BC}$ and has been confirmed to have good reliability in Chinese populations [39]. The scale contains 24 items and adopts a four-point scale from 1 (very strongly disagree) to 4 (very strongly agree), with a higher score indicating severe social stigma.

\section{Sociodemographic and clinical characteristic}

Sociodemographic characteristics were included in a set of self-administered questionnaires. In addition, medical information was collected from their clinical records. Participants' sociodemographic and clinical information was collected, including age, residence, educational background, marital status, employment, income, children, period, smoking, drinking, religious faith, time since diagnosis, cancer stage (disease stage at diagnosis) and distant metastasis (subsequent development of distant metastases).

\section{Statistical analysis}

First, Pearson correlation analysis was conducted to analyse the correlation between HRQOL and the continuous variables. T-tests and ANOVA were performed to examine the difference between HRQOL and the classification variables. Next, multivariable linear regression analysis was conducted to identify significant factors of HRQOL among the relational factors. In linear regression, HRQOL was regarded as a dependent variable, and social constraints, social support and social stigma were regarded as independent variables. In Model 1, social constraints were entered. Then, social support and stigma were added to Models 2 and 3, respectively. Finally, an adjusted Model 4 was performed to control for potential confounders according to univariate analysis $(P<0.25)$. A $P$ value less than 0.05 was considered statistically significant (two-tailed) in the linear regression model.

SPSS for Windows (22.0) was used to conduct all the statistical analyses in the present study.

\section{Results}

Reliability of assessment scales

All scales presented good internal consistency in the present study: Cronbach's alpha coefficient $=0.890$ for FACT-B, 0.909 for SCS-15, 0.964 for MSPSS and 0.955 for SIS.

\section{Level of continuous variables}

The average age of the participants was 48.05 $(\mathrm{SD}=10.24)$ and ranged from 30 to 78 . The total FACTB scores ranged from 46 to 133 , with a mean score of $96.05(\mathrm{SD}=18.70)$. The mean scores of social constraints, social support and social stigma were $23.06(\mathrm{SD}=8.38)$, $61.11(\mathrm{SD}=15.49)$ and $47.99(\mathrm{SD}=12.94)$, respectively (Table 2).

\section{Risk factors for HRQOL}

Table 3 presents the relationships between HRQOL and each variable. BC patients' HRQOL was possibly related to the following variables: patients who had children, religious faith, normal period, short time after diagnosis, and non-smoking status had better HRQOL $(P<0.25)$. Social constraints $(r=-0.512, P<0.01)$ and stigma $(r=-0.434, P<0.01)$ were negatively correlated with HRQOL; social support $(r=0.498, P<0.01)$ was positively associated with HRQOL.

Table 4 reports the results of the multivariable linear regression analysis. In Model 1, social constraints (Beta $=-0.512, P<0.001)$ were significantly and negatively associated with HRQOL and explained 25.7\% of the variance in HRQOL. In Model 2, social support (Beta $=0.374, \quad P<0.001)$ was significantly and positively associated with HRQOL, while social constraints $($ Beta $=-0.396, P<0.001)$ were still negatively related to HRQOL. Additionally, the linear combination of variables in Model 2 explained 38.0\% of the variance

Table 2 Scores of continuous variables

\begin{tabular}{llr}
\hline Variables & Mean & \multicolumn{1}{c}{ SD } \\
\hline FACT-B total score & 96.05 & 18.70 \\
Social constraints & 23.60 & 8.38 \\
Social support & 61.11 & 15.49 \\
Social stigma & 47.99 & 12.94 \\
\hline
\end{tabular}

FACT-B total score $=P W B+S W B+E W B+F W B+B C S$ 
Table 3 Relationship among HRQOL and univariable

\begin{tabular}{|c|c|c|}
\hline Variables & $\begin{array}{l}\text { FACT-B total score } \\
\text { Mean (SD) }\end{array}$ & $P$ \\
\hline Age $^{c}$ & - & 0.732 \\
\hline Social constraints ${ }^{c}$ & - & $<0.01$ \\
\hline Social support ${ }^{c}$ & - & $<0.01$ \\
\hline Social stigma ${ }^{c}$ & - & $<0.01$ \\
\hline Residence & - & 0.774 \\
\hline Rural area & $96.90(21.11)$ & \\
\hline City & $95.80(18.03)$ & \\
\hline Education background & & 0.690 \\
\hline Junior middle and below & $94.11(19.52)$ & \\
\hline Senior middle school & $97.08(17.70)$ & \\
\hline College and above & $96.96(19.96)$ & \\
\hline Marriage status & & 0.777 \\
\hline Single/divorced/widowed/separated & $94.95(22.22)$ & \\
\hline Married/cohabited & $96.24(18.12)$ & \\
\hline Employment & & 0.571 \\
\hline Yes & $97.73(17.78)$ & \\
\hline No & $93.59(21.79)$ & \\
\hline Retirement & $95.79(17.04)$ & \\
\hline Family per capita monthly income (CNY) & & 0.483 \\
\hline Less than 3000 & $94.05(19.87)$ & \\
\hline $3000-5000$ & $98.60(17.79)$ & \\
\hline More than 5000 & $96.23(17.88)$ & \\
\hline Children & & 0.052 \\
\hline No & $85.00(20.67)$ & \\
\hline Yes & $96.93(18.33)$ & \\
\hline Religious faith & & 0.251 \\
\hline No & $96.57(18.64)$ & \\
\hline Yes & 89.50 (19.18) & \\
\hline Period & & 0.232 \\
\hline Normal & $100.47(19.16)$ & \\
\hline Disorder & $96.38(21.82)$ & \\
\hline Amenorrhea & $94.10(17.76)$ & \\
\hline Smoking & & 0.095 \\
\hline No & $96.67(18.73)$ & \\
\hline Yes & $84.57(14.81)$ & \\
\hline Drinking & & 0.279 \\
\hline No & $94.85(18.15)$ & \\
\hline Yes & $105.50(18.53)$ & \\
\hline Quitting & $99.00(20.84)$ & \\
\hline Time since diagnosis & & 0.189 \\
\hline Half year or below & $92.57(19.30)$ & \\
\hline Half to 2 years & $99.26(18.53)$ & \\
\hline More than 2 years & $95.44(17.65)$ & \\
\hline Distant metastasis $^{\mathrm{a}}$ & & 0.430 \\
\hline No & $94.72(19.40)$ & \\
\hline Yes & $97.27(18.08)$ & \\
\hline Cancer stage $^{b}$ & & 0.973 \\
\hline | & 95.98 (18.48) & \\
\hline$\|$ & 96.09 (18.92) & \\
\hline
\end{tabular}

Table 3 (continued)

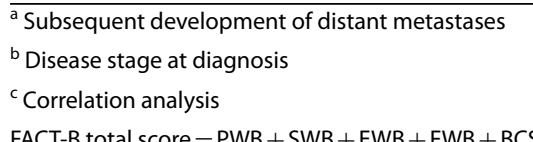

in HRQOL. In Model 3, social support (Beta $=0.375$, $P<0.001)$ was found to positively impact HRQOL, but social stigma (Beta $=-0.258, P=0.001$ ) was negatively related to HRQOL. Social constraints (Beta $=-0.280$, $P<0.001)$ were still significantly and negatively associated with HRQOL. The linear combination of variables in Model 3 explained $42.9 \%$ of the variance in HRQOL. Finally, confounders included in Model 4 were children, religious faith, period, smoking, and time since diagnosis. Social constraints $($ Beta $=-0.301, P<0.001)$, support $($ Beta $=0.330, P<0.001)$, and stigma (Beta $=-0.241$, $P<0.001)$ were significantly associated with HRQOL, which explained $44.3 \%$ of the variance in HRQOL.

\section{Discussion}

The mean FACT-B score was $96.05(\mathrm{SD}=18.70)$ in Chinese women with $\mathrm{BC}$. The level of overall HRQOL in the current study was lower than that in Americans in BC studies that adopted the same measurement tool [4143]. In addition, Lu et al. found that Chinese BC patients reported lower HRQOL than their American counterparts [35]. Lu et al. suggested that Chinese BC patients undergoing more aggressive treatment or taking drugs may be likely to experience more adverse side effects [35]. Additionally, strategies of symptom control may be different. Despite the fact that there are affordable and advanced treatments to obtain better cancer care for Chinese $\mathrm{BC}$ patients, our results showed that patients with BC still suffer poorer HRQOL than patients in Western countries. Thus, identifying psychological factors is a top priority among Chinese $\mathrm{BC}$ patients.

The results of our study reported no association of sociodemographic and clinical variables with HRQOL among Chinese BC patients. However, other studies have suggested that SES indicators are uniquely associated with overall HRQOL and its dimensions in BC patients [9]. SES is defined as a multidimensional construct containing social position (education), economic status (income) and work conditions (occupation) [44]. For example, Xia et al. reported that financial difficulties were a stronger predictor of impaired global HRQOL for BC patients. You et al. also found a significant association of education and income with different aspects of HRQOL among BC patients [9].

The findings in our study presented a strong adverse effect of social constraints on HRQOL among Chinese 
Table 4 Possible related factors of HRQOL

\begin{tabular}{|c|c|c|c|c|c|c|c|c|}
\hline \multirow[t]{2}{*}{ Variables } & \multicolumn{2}{|l|}{ Model 1} & \multicolumn{2}{|l|}{ Model 2} & \multicolumn{2}{|l|}{ Model 3} & \multicolumn{2}{|l|}{ Model 4} \\
\hline & Beta & $P$ & Beta & $P$ & Beta & $P$ & Beta & $P$ \\
\hline Social constraints & -0.512 & $<0.001$ & -0.396 & $<0.001$ & -0.280 & $<0.001$ & -0.301 & $<0.001$ \\
\hline Social support & & & 0.374 & $<0.001$ & 0.375 & $<0.001$ & 0.330 & $<0.001$ \\
\hline Social stigma & & & & & -0.258 & 0.001 & -0.241 & 0.001 \\
\hline Children (no/yes) & & & & & & & 0.120 & 0.083 \\
\hline Religious faith (no/yes) & & & & & & & -0.119 & 0.071 \\
\hline Smoking (No/Yes) & & & & & & & -0.016 & 0.819 \\
\hline Period $^{a}$ & & & & & & & -0.082 & 0.229 \\
\hline Time $^{b}$ & & & & & & & 0.092 & 0.167 \\
\hline Adjusted $R^{2}$ & 0.257 & & 0.380 & & 0.429 & & 0.443 & \\
\hline
\end{tabular}

${ }^{a}$ period (normal, disorder, amenorrhea)

${ }^{\mathrm{b}}$ Time (half year or below, half to 2 years, more than 2 years)

$\mathrm{BC}$ patients, which was in accordance with the results in Caucasian [45] and Chinese American [24] patients with BC. Namely, patients with more social constraints tend to have worse HRQOL. Their abilities to perceive and ask for the social support they need and to express emotion are limited in a negative environment [25]. Finally, the way patients perceive their social environment seems to influence perceived stress [37]. For example, patients with a negative perception of their environment are more likely to consider a cancer diagnosis a more threatening, less manageable and stressful event, which results in adverse outcomes [37]. Additionally, our results revealed that social constraints among Chinese BC patients $($ Mean $=1.82)$ were higher than Caucasian BC patients $($ Mean $=1.77)$ in previous study [45], but were lower than those reported by Chinese American BC patients $(M e a n=2.02)$ [24]. In Chinese culture, cancer is considered "bad luck", and emotional expression is rare among Chinese families, which implies a high level of social constraints in Chinese BC patients. Hence, future research should adopt a cross-cultural design to directly compare the differences in social constraints in different countries.

Our study found that social support was positively associated with HRQOL, and the association of social support with HRQOL has been widely examined among BC patients $[9,15]$. In addition, social support is beneficial for patients with different cancer types [46]. Patients with sufficient social support have a platform to share and communicate, which helps them adapt psychological changes and reconstruct cognitive processes. With regard to social stigma, the current study found that it was negatively related to HRQOL in BC patients. Previous research has also reported similar findings [14]. Some studies suggest that stigma may cause cognitive changes, including increases in negative thoughts and decreases in positive thoughts. These changes have an adverse influence on Chinese BC patients' HRQOL. Therefore, psychological interventions to enhance the HRQOL of Chinese BC patients may attempt to foster social support and reduce social stigma and constraints.

\section{Implications}

According to the findings from our study, some psychological interventions should be emphasized. Our study indicated the crucial psychological factors of HRQOL among Chinese $\mathrm{BC}$ patients. Our findings suggested that social constraints (e.g., emotional disclosure) and stigma are still common conditions in Chinese patients owing to traditional culture. Thus, intervention strategies focusing on less personal disclosure should be adopted. For instance, Chu et al. [47] found that expressive writing interventions effectively contribute to avoiding social constraints and decreasing posttraumatic stress disorder (PTSD) among Chinese American BC patients. Moreover, the findings of the current study acknowledge interventions based on positive social support to increase BC patients' HRQOL. For example, families, friends and medical staff should immediately respond to their needs and questions in as many ways as possible.

\section{Limitations}

Some limitations exist in the present study. First, this study had a cross-sectional design, and causal conclusions could not be drawn between social constraints, support, stigma and HRQOL among Chinese BC patients. Therefore, further research should adopt a longitudinal design to confirm these associations. Second, self-report surveys and convenience samples may limit representativeness in our study. Further studies with more representative samples should be performed. 
Third, the current study was performed in Liaoning Province and conducted in a small sample of patients. Thus, the participants in our study might not be representative of the population of $\mathrm{BC}$ patients. Finally, although our study found an adverse impact of social constraints on HRQOL among Chinese BC patients, the psychological pathways underlying this association are unclear. Future research should aim to explore the psychological pathways between social constraints and HRQOL.

\section{Conclusion}

Our study is the first attempt to examine the relationship between social constraints and overall HRQOL among Chinese $\mathrm{BC}$ patients. The findings from the current study suggest that Chinese BC patients' HRQOL needs to be enhanced after treatment. Social constraints have a strong association with HRQOL, while social support and stigma are also important factors. Given the above results, intervention strategies focusing on less personal disclosure should be considered to avoid social constraints and improve HRQOL among Chinese BC patients.

\section{Abbreviations}

BC: Breast cancer; HRQOL: Health-related quality of life; SD: Standard deviation; SES: Socioeconomic status; CNY: Chinese Yuan; FACT-B: Functional Assessment of Cancer Therapy-Breast; SCS-15: 15-Item Social Constraints Scale; MSPSS: Multidimensional Scale of Perceived Social Support; SIS: Social Impact scale; PWB: Physical well-being; SFWB: Social/family well-being; EWB: Emotional well-being; FWB: Functional well-being; BCS: Additional concerns.

\section{Acknowledgements}

All authors would like to gratitude the patients who participate in the survey, and the search fellows who collect, manage and analyze data of the study. All authors read and approved the final manuscript.

\section{Authors' contributions}

CYC and XXW conceived and designed the survey. CYC and LW performed the investigation. CYC and XXW analyzed the data. CYC wrote the original paper. XXW revised the paper. All authors read and approved the final manuscript.

\section{Funding}

There was no funding support.

\section{Availability of data and materials}

The dataset in this study is available from the corresponding author on reasonable request.

\section{Declarations}

\section{Ethical approval and consent to participate}

All patients provided their informed written consent. The study was approved by the Ethics Committee on Human Experimentation of China Medical University, and the study procedures were in accordance with ethical standards.

\section{Consent for publication}

Not applicable.

\section{Competing interest}

All authors declare that there are no conflicts of interest in this work.

\section{Author details}

${ }^{1}$ Department of Social Medicine, School of Public Health, China Medical University, No. 77 Puhe Road, Shenyang North New Area, Shenyang 110122, Liaoning, People's Republic of China. ${ }^{2}$ Medical Basic Experimental Teaching Center, China Medical University, No. 77 Puhe Road, Shenyang North New Area, Shenyang 110122, Liaoning, People's Republic of China.

Received: 29 June 2021 Accepted: 26 September 2021

Published online: 12 October 2021

\section{References}

1. World Health Organization. https://gco.iarc.fr/today/fact-sheets-popul ations (2020).

2. World Health Organization. https://gco.iarc.fr/today/online-analysis-table (2020).

3. Sedlmayer F, Sautter-Bihl ML, Budach W, et al. DEGRO practical guidelines: radiotherapy of breast cancer I: radiotherapy following breast conserving therapy for invasive breast cancer. Strahlenther Onkol. 2013;189(10):82533. https://doi.org/10.1007/s00066-013-0437-8.

4. Zeng $\mathrm{H}$, Chen W, Zheng $\mathrm{R}$, et al. Changing cancer survival in China during 2003-15: a pooled analysis of 17 population-based cancer registries. Lancet Glob Health. 2018;6(5):e555-67. https://doi.org/10.1016/S2214109X(18)30127-X

5. Doege $\mathrm{D}$, Thong MS, Koch-Gallenkamp $\mathrm{L}$, et al. Health-related quality of life in long-term disease-free breast cancer survivors versus female population controls in Germany. Breast Cancer Res Treat. 2019;175(2):499-510. https://doi.org/10.1007/s10549-019-05188-x.

6. Bower JE, Meyerowitz BE, Desmond KA, Bernaards CA, Rowland JH, Ganz PA. Perceptions of positive meaning and vulnerability following breast cancer: predictors and outcomes among long-term breast cancer survivors. Ann Behav Med. 2005;29(3):236-45. https://doi.org/10.1207/s1532 4796abm2903_10.

7. Kendall $A R$, Mahue-Giangreco M, Carpenter CL, Ganz PA, Bernstein L. Influence of exercise activity on quality of life in long-term breast cancer survivors. Qual Life Res. 2005;14(2):361-71. https://doi.org/10.1007/ s11136-004-1468-5.

8. Xia J, Tang Z, Deng Q, Yang R, Wang J, Yu J. Predictors of the quality of life in Chinese breast cancer survivors. Breast Cancer Res Treat. 2018;167(2):537-45. https://doi.org/10.1007/s10549-017-4512-1.

9. You J, Wang C, Yeung NCY, Lu Q. Socioeconomic status and quality of life among Chinese American breast cancer survivors: the mediating roles of social support and social constraints. Psychooncology. 2018;27(7):1742-9. https://doi.org/10.1002/pon.4719.

10. Hauth F, De-Colle C, Weidner N, Heinrich V, Zips D, Gani C. Quality of life and fatigue before and after radiotherapy in breast cancer patients. Strahlenther Onkol. 2021;197(4):281-7. https://doi.org/10.1007/ s00066-020-01700-1.

11. Mejía-Rojas ME, Contreras-Rengifo A, Hernández-Carrillo M. Quality of life in women treated with chemotherapy for breast cancer in Cali, Colombia. Biomedica. 2020;40(2):349-61. https://doi.org/10.7705/biomedica.4971.

12. Cui Y, Shu XO, Gao Y, Cai H, Wen W, Ruan ZX, Jin F, Zheng W. The longterm impact of medical and socio-demographic factors on the quality of life of breast cancer survivors among Chinese women. Breast Cancer Res Treat. 2004;87(2):135-47. https://doi.org/10.1023/B:BREA.0000041620. 76871.97

13. Yeung NCY, Lu Q, Mak WWS. Self-perceived burden mediates the relationship between self-stigma and quality of life among Chinese American breast cancer survivors. Support Care Cancer. 2019;27(9):3337-45. https:// doi.org/10.1007/s00520-018-4630-2.

14. Wong CCY, Pan-Weisz BM, Pan-Weisz TM, Yeung NCY, Mak WWS, Lu Q. Self-stigma predicts lower quality of life in Chinese American breast cancer survivors: exploring the mediating role of intrusive thoughts and posttraumatic growth. Qual Life Res. 2019;28(10):2753-60. https://doi. org/10.1007/s11136-019-02213-w. 
15. Strayhorn SM, Bergeron NQ, Strahan DC, Villines D, Fitzpatrick V, Watson KS, Khanna A, Molina Y. Understanding the relationship between positive and negative social support and the quality of life among African American breast cancer survivors. Support Care Cancer. 2021. https://doi.org/ 10.1007/s00520-021-06098-9.

16. Gottlieb BH, Bergen AE. Social support concepts and measures. J Psychosom Res. 2010;69(5):511-20. https://doi.org/10.1016/j.jpsychores.2009.10. 001.

17. Cohen S, Wills TA. Stress, social support, and the buffering hypothesis. Psychol Bull. 1985;98(2):310-57.

18. Cataldo JK, Slaughter R, Jahan TM, Pongquan VL, Hwang WJ. Measuring stigma in people with lung cancer: psychometric testing of the cataldo lung cancer stigma scale. Oncol Nurs Forum. 2011;38(1):E46-54. https:// doi.org/10.1188/11.ONF.E46-E54.

19. Hatzenbuehler ML, Phelan JC, Link BG. Stigma as a fundamental cause of population health inequalities. Am J Public Health. 2013;103(5):813-21. https://doi.org/10.2105/AJPH.2012.301069.

20. Major B, O'Brien LT. The social psychology of stigma. Annu Rev Psychol. 2005;56:393-421. https://doi.org/10.1146/annurev.psych.56.091103. 070137.

21. Kang NE, Kim HY, Kim JY, Kim SR. Relationship between cancer stigma, social support, coping strategies and psychosocial adjustment among breast cancer survivors. J Clin Nurs. 2020;29(21-22):4368-78. https://doi. org/10.1111/jocn.15475.

22. Wang QX, Bai Y, Lu GF, Zhang CY. Perceived health-related stigma among patients with breast cancer. Chin Nurs Res. 2017;4(4):158-61. https://doi. org/10.1016/j.cnre.2017.10.002.

23. Şengün İnan F, Üstün B. Experiences of Turkish survivors of breast cancer: Neuman systems model perspective. Jpn J Nurs Sci. 2016;13(4):466-77. https://doi.org/10.1111/jjns.12129.

24. You J, Lu Q. Social constraints and quality of life among Chinesespeaking breast cancer survivors: a mediation model. Qual Life Res. 2014;23(9):2577-84. https://doi.org/10.1007/s11136-014-0698-4.

25. Wong CCY, Warmoth K, Ivy S, Cheung B, Lu Q. Relation of social constraints on disclosure to adjustment among Chinese American cancer survivors: a multi-processes approach. Psychooncology. 2018;27(3):97782. https://doi.org/10.1002/pon.4604.

26. Lepore SJ, Revenson TA. Social constraints on disclosure and adjustment to cancer. Soc Pers Psychol Compass. 2007;1(1):313-33. https://doi.org/ 10.1111/j.1751-9004.2007.00013.x.

27. Lepore SJ. A social-cognitive processing model of emotional adjustment to cancer. In: Baum A, Andersen BL, editors. Psychosocial interventions for cancer. Washington, DC: American Psychological Association; 2001. p. 99-116.

28. Braitman AL, Derlega VJ, Henson JM, et al. Social constraints in talking about diabetes to significant others and diabetes self-care: a socialcognitive processing perspective. J Soc Clin Psychol. 2008;27(9):949-69. https://doi.org/10.1521/jscp.2008.27.9.949.

29. Gabriele JM, Walker MS, Gill DL, Harber KD, Fisher EB. Differentiated roles of social encouragement and social constraint on physical activity behavior. Ann Behav Med. 2005;29(3):210-5. https://doi.org/10.1207/s1532 4796abm2903_7.

30. Yeung NCY, Wang LJ, Ji L, Lu Q, Lu G. Difficulties in identifying and describing feelings, social constraints, affect, and functional well-being among Chinese breast cancer patients: a mediation model. Eur J Oncol Nurs. 2020;47:101760. https://doi.org/10.1016/j.ejon.2020.101760.

31. Wei M, Su JC, Carrera S, Lin SP, Yi F. Suppression and interpersonal harmony: a cross-cultural comparison between Chinese and European Americans. J Couns Psychol. 2013;60(4):625-33. https://doi.org/10.1037/ a0033413.
32. Chen SX, Cheung FM, Bond MH, et al. Decomposing the construct of ambivalence over emotional expression in a Chinese cultural context. Eur J Pers. 2010. https://doi.org/10.1002/per.538.

33. Wan C, Zhang D, Yang Z, Tu X, Tang W, Feng C, Wang H, Tang X. Validation of the simplified Chinese version of the FACT-B for measuring quality of life for patients with breast cancer. Breast Cancer Res Treat. 2007;106(3):413-8. https://doi.org/10.1007/s10549-007-9511-1.

34. Brady MJ, Cella DF, Mo F, Bonomi AE, Tulsky DS, Lloyd SR, Deasy S, Cobleigh M, Shiomoto G. Reliability and validity of the functional assessment of cancer therapy-breast quality-of-life instrument. J Clin Oncol. 1997;15(3):974-86. https://doi.org/10.1200/JCO.1997.15.3.974.

35. Lu Q, You J, Kavanagh A, Warmoth K, Meng Z, Chen Z, Chandwani KD, Perkins GH, McQuade JL, Raghuram NV, Nagarathna R, Liao Z, Nagendra HR, Chen J, Guo X, Liu L, Arun B, Cohen L. Differences in quality of life between American and Chinese breast cancer survivors. Support Care Cancer. 2016;24(9):3775-82. https://doi.org/10.1007/s00520-016-3195-1.

36. Lepore SJ, Ituarte PH. Optimism about cancer enhances mood by reducing negative social interactions. Cancer Res Ther Control. 1999;8:165-74.

37. Yeung NCY, Ramirez J, Lu Q. Perceived stress as a mediator between social constraints and sleep quality among Chinese American breast cancer survivors. Support Care Cancer. 2017;25(7):2249-57. https://doi. org/10.1007/s00520-017-3632-9.

38. Zimet GD, Dahlem NW, Zimet SG, Farley GK. The multidimensional scale of perceived social support. J Pers Assess. 1988;52:30-41.

39. Zhang Y, Cui C, Wang Y, Wang L. Effects of stigma, hope and social support on quality of life among Chinese patients diagnosed with oral cancer: a cross-sectional study. Health Qual Life Outcomes. 2020;18(1):112. https://doi.org/10.1186/s12955-020-01353-9.

40. Fife BL, Wright ER. The dimensionality of stigma: a comparison of its impact on the self of persons with HIV/AIDS and cancer. J Health Soc Behav. 2000;14:50-67.

41. Morrill EF, Brewer NT, O'Neill SC, Lillie SE, Dees EC, Carey LA, Rimer BK. The interaction of post-traumatic growth and post-traumatic stress symptoms in predicting depressive symptoms and quality of life. Psychooncology. 2008;17(9):948-53. https://doi.org/10.1002/pon.1313.

42. Wildes KA, Miller AR, de Majors SS, Ramirez AG. The religiosity/spirituality of Latina breast cancer survivors and influence on health-related quality of life. Psychooncology. 2009;18(8):831-40. https://doi.org/10.1002/pon. 1475.

43. Deshields T, Tibbs T, Fan MY, Taylor M. Differences in patterns of depression after treatment for breast cancer. Psychooncology. 2006;15(5):398406. https://doi.org/10.1002/pon.962.

44. Dutton DB, Levine S. Overview, methodological critique, and reformulation. In: Bunker JB, Gomby DS, Kehrer BH, editors. Pathways to health. Menlo Park: The Henry J. Kaiser Family Foundation; 1989. p. 29-69.

45. Cordova MJ, Cunningham LL, Carlson CR, Andrykowski MA. Social constraints, cognitive processing, and adjustment to breast cancer. J Consult Clin Psychol. 2001;69(4):706-11.

46. Zhang L, Lu Y, Qin Y, Xue J, Chen Y. Post-traumatic growth and related factors among 1221 Chinese cancer survivors. Psychooncology. 2020;29(2):413-22. https://doi.org/10.1002/pon.5279.

47. Chu Q, Wu IHC, Lu Q. Expressive writing intervention for posttraumatic stress disorder among Chinese American breast cancer survivors: the moderating role of social constraints. Qual Life Res. 2020;29(4):891-9. https://doi.org/10.1007/s11136-019-02385-5.

\section{Publisher's Note}

Springer Nature remains neutral with regard to jurisdictional claims in published maps and institutional affiliations. 